\title{
IRONÍA Y DISTANCIAMIENTO: EL MONÓLOGO DRAMÁTICO EN JAIME GIL DE BIEDMA Y WYSTAN HUGH AUDEN
}

\author{
María Gracia RODRÍGUEZ FERNÁNDEZ \\ Universidad de Granada
}

$\mathrm{L}$ os primeros ejemplos de monólogos dramáticos surgieron a mediados del siglo XIX, en torno a 1842, en Inglaterra, para reaccionar contra el concepto de la poesía como un vehículo de emociones puramente personales. En palabras de Joana Sabadell Nieto, ésta es una técnica en la que «el poeta da voz y crea un personaje para mostrar los hechos desde dentro, es decir, para producir un efecto de inmediatez y objetividad manteniéndose, a la vez, distante» (Sabadell Nieto, 1991: 178). De manera que el monólogo dramático no implica necesariamente la supresión del «yo» poético, sino su expresión indirecta por medio de un personaje. Este personaje puede proceder del mundo de la cultura, o bien de la historia, y el poeta lo escoge a fin de objetivar su propia voz, lo que le permite asumir una identidad diferente a la suya. Este recurso está, por tanto, muy presente en la poesía moderna, al ser un elemento crucial en la elaboración del distanciamiento irónico.

El principal estudio acerca del origen del monólogo dramático aparece en la obra de Robert Langbaum The Poetry of Experience. The Dramatic Monologue in Modern Literary Tradition (1957), donde el autor expone cómo esta técnica emerge en un momento de crisis de identidad que tiene lugar a finales del Romanticismo. Esto no deja de impresionar, pues, como explica la profesora Joana Sabadell Nieto, «el primer germen de la muerte del yo lírico está arraigado en el máximo apogeo de su uso, en el Romanticismo» (Sabadell Nieto, 1991: 180). Dos autores postrománticos, como Robert Browning y Lord Alfred Tennyson, son pioneros en la práctica del monólogo dramático en sus composiciones. De hecho, el crítico americano Robert Langbaum lo apunta en su obra cumbre del siguiente modo:

The standard account of the dramatic monologue is that Browning and Tennyson conceived it as a reaction against the romantic confessional style. The two poets cannot explain the coincidence that, working independently, they both arrived at the same form and produced at first try dramatic monologues so perfect (Browning's «My Last Duchess» and Tennyson's «Ulysses» and «St Simeon Stylites»). However, Tennyson goes much farther than Browning in dealing in his successful dramatic monologues with an emotional perversity that verge on the pathological (Langbaum, 1963: 86-87). 
De manera que Browning y Tennyson utilizan el monólogo dramático como un modo de reacción contra el Romanticismo. Dicho de otro modo, desean romper con el uso del «yo» poético como única forma de expresar sus sentimientos y crean, para ello, un personaje. Sí que es cierto que Robert Browning y Lord Alfred Tennyson inician esta técnica, pero están seguidos muy de cerca por Ezra Pound y T. S. Eliot. No obstante, Robert Langbaum explica las contribuciones de Eliot a la técnica del monólogo dramático como aparece a continuación:

Eliot has little to say in favour of Browning, the dramatic monologue has been the main form in his work until he assumed what appears to be a personal voice in the series of religious meditations beginning with «Ash Wednesday». The dramatic monologue is proportionately as important in Eliot's work as in Browning's, Eliot having contributed more to the development of the form than any poet since Browning. Certainly «Prufrock», «Portrait of a Lady», «Gerontion», «Journey of the Magi», «A Song for Simeon» and «Marina» do as much credit to the dramatic monologue as anything of Browning's; while in «The Waste Land» Eliot has opened new possibilities for the form by constructing with a collage of voices the dramatic monologue of a modern consciousness that is also a cultural memory (Langbaum, 1963: 77).

En efecto, T. S. Eliot es una figura muy importante en la creación de los monólogos dramáticos, porque desarrolla y abre nuevas posibilidades de expresión dialógica del «yo» a través de otros tipos de voces ficcionales. Sin embargo, a pesar de sus aportaciones, tanto Ezra Pound como T. S. Eliot utilizan el monólogo dramático a la manera de Robert Browning. Pero no son los únicos, otros autores también colaboran en la evolución de dicha técnica, destacando entre los extranjeros a poetas como, por ejemplo, Thomas Hardy, Walt Whitman, William Butler Yeats, Dylan Thomas, Amy Lawrence Lowell, Robert Lowell y Wystan Hugh Auden, entre otros; mientras que en la poesía española esta técnica arranca con Luis Cernuda. De hecho, el conocimiento que el autor sevillano adquiere de los primeros casos de monólogos dramáticos en la poesía contemporánea inglesa es clave, para que algunos miembros de la llamada generación del cincuenta conociesen y empleasen esta técnica, como le ocurre principalmente a Francisco Brines, José Ángel Valente y Jaime Gil de Biedma.

De manera que la notable influencia de la obra de Robert Langbaum sobre la poesía de Wystan Hugh Auden y de Jaime Gil de Biedma nos lleva a estudiar la relación de estos dos autores con el procedimiento del monologo dramático. En este caso, es incuestionable el conocimiento directo que Biedma tiene del tipo de literatura que practica Auden, con cuya poesía entra en contacto tras leer Collected Shorter Poems (1930-1944), durante su estancia en Oxford. Desde entonces desarrolla un gran interés por la poética de este autor moderno, a quien admira hasta el punto de identificarse con él y con quien comparte la misma inquietud por la oposición entre las dimensiones públicas y privadas del individuo.

Pero siguiendo con el estudio del monólogo dramático como enmascaramiento, según la profesora Shirley Mangini González, éste se presenta de dos formas posibles, como son:

Los desdoblamientos y las proyecciones del yo para asegurar el distanciamiento irónico del personaje poético. Al mismo tiempo, este juego de ocultación-postración y transformación del sujeto lírico proyecta un perspectivismo sobre el texto que, finalmente, pone en duda la posibilidad de un conocimiento racional de la realidad (Mangini González, 1980: 72-73). 
De esta forma, para objetivarse en sus poemas, W. H. Auden no solamente emplea la tercera persona del singular o el desdoblamiento en el tú, sino que practica, a su vez, la técnica del monólogo dramático en sus más famosas composiciones como, por ejemplo, Letter to a Wound (1931), Musée des Beaux Arts (1938) y For the Time Being: A Christmas Oratorio (1941-42). Éste es uno de los poemas más largos del autor angloamericano, pues consta de mil quinientos versos y está compuesto por una serie de monólogos dramáticos que permiten a Auden volver a contar la historia de la Navidad, mediante la cual pretende descubrir su lugar en el mundo. Además, debe mencionarse también The Sea and the Mirror: A Commentary on Shakespeare's The Tempest (1942-44). En todos estos poemas, como dice John G. Blair, «Wystan Hugh Auden has demonstrated impressive facility in speaking through any sort of dramatic persona or mask» (Blair, 1965: 120). Para probar lo dicho, analizaremos el prólogo de The Sea and the Mirror, la obra que, según Esther Sánchez Pardo, «marcaba la diferencia entre el joven Auden inglés y el que se convertiría en el maduro poeta norteamericano» (Sánchez Pardo, 2007: 94). The Sea and the Mirror: A Commentary on Shakespeare's The Tempest es un extenso poema en verso y en prosa, en el que Auden ofrece una reflexión acerca de la relación que existe entre la vida y el arte. Para ello, selecciona a varios personajes de la obra The Tempest de William Shakespeare, a los que añade dos personajes de su propia invención, como son el maestro de pista, «The Stage Manager», y Prompter, y mediante una serie de monólogos dramáticos, el autor angloamericano asume su personalidad.

The Sea and the Mirror: A Commentary on Shakespeare's The Tempest consta de cinco partes. El poema se abre con un prefacio, seguido de una primera parte titulada «Prospero to Ariel», una segunda que lleva por nombre «The Supporting Cast, Sotto Voce», una tercera que, además de ser la más larga, es la única escrita en prosa, «Caliban to the Audience», y, finalmente, el epílogo que cierra la composición. Para estudiar el monólogo dramático en este poema, será analizado el prefacio de esta obra. En él, Wystan Hugh Auden reflexiona acerca de la vida y del arte. Por esa razón, pone en escena al maestro de pista, figura poética a través de la cual ejerce el distanciamiento irónico necesario para la ejecución del monólogo dramático. Este personaje es el encargado de explicar a los críticos cómo la complejidad de la vida imposibilita, de algún modo, su definición, motivo por el cual ni el arte ni la ciencia pueden dar una explicación convincente de sus misterios. Así que las cuatro estrofas que componen el prólogo son un intento de respuesta para esclarecer la existencia del hombre.

\title{
PREFACE
}

(The STAGE MANAGER to the Critics)

\author{
The aged catch their breath, \\ For the nonchalant couple go \\ Waltzing across the tightrope \\ As if there were no death \\ Or hope of falling down; \\ The wounded cry as the clown \\ Doubles his meaning, and $\mathrm{O}$ \\ How the dear little children laugh \\ When the drums roll and the lovely \\ Lady is sawn in half (Auden, 1976: 311).
}


En la primera estrofa, el maestro de pista les sugiere a los críticos que examinen el grado de veracidad de una función de circo. Es decir, quiere hacerles ver la relación que existe entre el espectáculo circense y la vida presentada mediante la metáfora del circo, donde el hombre, al igual que los actores, en ocasiones, también actúa. Por tanto, plantea el trabajo de los artistas del circo, presentando los shows típicos de un espectáculo, donde los actores interpretan, pero transmitiendo una sensación de autenticidad que llega a los niños, «dear little children [who] laugh / When the drums roll and the lovely Lady is sawn in half». En conclusión, el maestro de pista presenta el arte y la vida como un circo, donde lo que nos llama la atención es un artificio que falsea la realidad, haciéndonos creer que es verdad.

\author{
O what authority gives \\ Existence its surprise? \\ Science is happy to answer \\ That the ghosts who haunts our lives \\ Are handy with mirrors and wire, \\ That song and sugar and fire, \\ Courage and come-hither eyes \\ Have a genius for taking pains. \\ But how does one think up a habit? \\ Our wonder, our terror remains (Auden, 1976: 311).
}

La segunda estrofa se abre con una pregunta que no sólo marca el inicio de una compleja reflexión sobre la autoría de la existencia del hombre, sino que también expone una de las máximas preocupaciones de Auden a lo largo de toda su obra poética, como es «oh, ¿qué autoridad da a la existencia su sorpresa?». En otras palabras, ¿a qué se debe la existencia del hombre? La ciencia responde al misterio de la vida, pero ni siquiera las leyes científicas adivinan la complejidad existencial del hombre, por lo que nuestro asombro, nuestro terror permanece, «our wonder, our terror remains». Sin embargo, la ciencia no es la única disciplina que pretende establecer una respuesta al enigma de la vida, sino que el arte también persigue un intento similar.

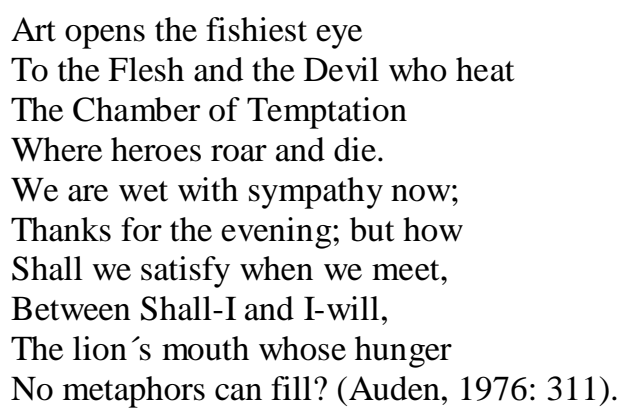

En la tercera estrofa, el maestro de pista introduce la incapacidad del arte para resolver los problemas de la vida, pues cualquier solución que proponga es un remedio insuficiente en comparación con la grandeza que encierra la existencia del hombre. En palabras de Margaret Boyd, «yet art cannot express the infinite variety of choices presented by life between the recognition of possibility and the actual choice» (Boyd, 1976: 20). Por esa razón, cuando el hombre se encuentra acechado por la duda 
entre «¿debería hacerlo?»y «lo haré», «between Shall-I and I-Will», ni el arte ni la ciencia pueden calmar su inquietud interna. De ahí que las dos disciplinas sean consideradas como armas ineficientes para curar el desasosiego del ser humano, identificado en este fragmento con la boca del león, «the lion's mouth», que no se sacia con metáforas.

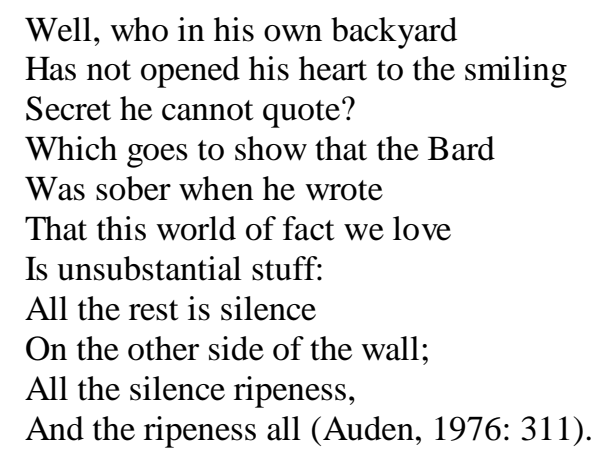

Por último, en la cuarta estrofa, el maestro de pista manifiesta la crueldad del mundo que amamos, ya que por más que el hombre se resigne, morirá. Dicho de otro modo, tanto para el maestro de pista como para Shakespeare, aludido en el texto con el apodo del Bardo, «the Bard», el hombre ama una materia insubstancial, «unsubstantial stuff» porque su vida acaba, aunque no quiera. Aunque se oponga, el ser humano es preso de lo que dictamine su destino, contra el que no puede luchar. Por esa razón, es mejor no buscar respuestas ni en la ciencia, ni en el arte, evitar la angustia de su existencia, simplemente aceptándola. En otras palabras, el mundo es un producto vacío, cuya falta de sustancia provoca silencio e inseguridad ante lo venidero. No obstante, el ser humano constata esto, cuando está al otro lado del muro, «on the other side of the wall», donde no le queda más remedio que afrontar su destino con madurez «ripeness» y sosiego, al no poder cambiar nada que la vida le depare.

En definitiva, el poeta angloamericano, a través del maestro de pista, personaje poético de quien asume la identidad en el prólogo, transmite un consejo a sus lectores como es que ellos deben, en palabras de Margaret Boyd Morgan, «to face their mortality and silently to seek within themselves for their true essence» (Boyd, 1976: 108). En otras palabras, el ser humano debe enfrentarse, con calma, a una búsqueda dentro de sí mismo. Dicha indagación lo conduce a su esencia natural, a su más profundo instinto, lo que le proporciona no sólo un pleno conocimiento de su ser, sino también el convencimiento de que inevitablemente va a morir. Por esa razón, es inútil estar permanentemente preocupado por su existencia, sobre la que no ejerce ningún poder.

A continuación, vamos a analizar A Lullaby (1972), un texto en el que el poeta dialoga consigo mismo. Pero en esta ocasión, la conversación adquiere un matiz distinto, y es que el distanciamiento irónico se produce por medio de dos personajes, como son la Madonna y el Bambino. En otras palabras, el «yo» poético se habla a sí mismo como si fuera una madre hablándole a un hijo, al que le está cantando una nana. Este es un ejemplo de monólogo dramático muy particular, porque lo acerca mucho al dialogismo. Sin embargo, nos hemos atenido al hecho empírico de que Wystan Hugh Auden no es una madre. Es decir, el personaje que habla no se identifica con el autor, puesto que es una madre. No 


\title{
María Gracia Rodríguez Fernández
}

obstante, este personaje carece de toda verosimilitud por las reflexiones que plantea, ya que éstas son impropias de su condición y de la situación en la que se encuentra.

\author{
A LULLABY \\ The din of work is subdued, \\ another day has westered \\ and mantling darkness arrived. \\ Peace! Peace! Devoid your portrait \\ of its vexations and rest: \\ Your daily round is done with, \\ you've gotten the garbage out, \\ answered some tiresome letters \\ and paid a bill by return, \\ all frettolosamente. \\ Now you have licence to lie, \\ naked, curled like a shrimplet, \\ jacent in bed, and enjoy \\ its cosy micro-climate: \\ Sing, Big Baby, sing lullaby (Auden, 1976: 672).
}

La voz poética es la materna, recurso que enfatiza la perspectiva irónica adoptada por el hablante, que se dirige al hijo, a quien le dice que el día ha concluido y que, al fin, la oscuridad como un manto, «mantling», ha llegado. Después de la tediosa rutina, de haber sacado la basura, de haber respondido algunas cartas aburridas y pagado una factura a vuelta de correo le llega el momento de descanso. Ahora puede desnudarse, enroscarse como un camarón y tumbarse en la cama, donde disfruta de su confortable microclima. El «yo» poético habla de sí mismo, pero lo hace como si fuera otra persona. Es decir, la voz poética es ambos personajes, tanto la madre que le dice al hijo, canta, grandullón, canta la nana, «Sing, Big Baby, sing lullaby», como el propio hijo. Además, «Big Baby» aparece escrito en mayúscula porque el niño al que le canta la nana, no es un niño, sino un adulto, el poeta.

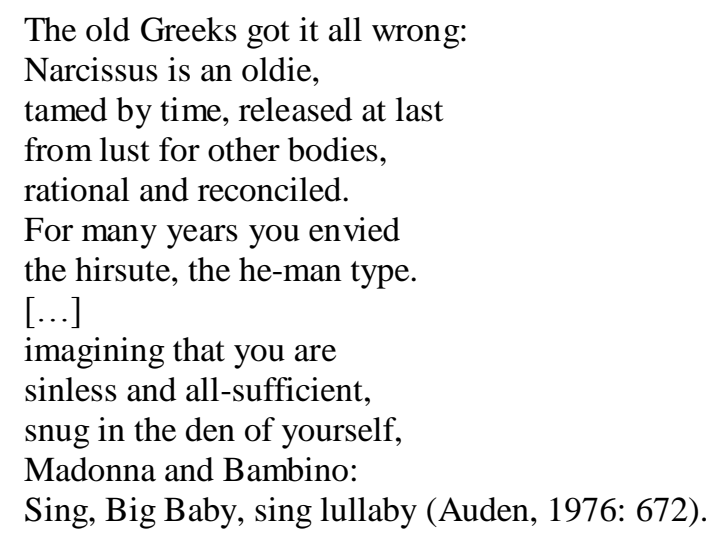

La madre se dirige al hijo para explicarle el error de los griegos, pues, para ella, todos estaban equivocados, porque Narciso realmente es un viejo domado por el tiempo, que está liberado de la lujuria de otros cuerpos. En esta ocasión, Auden vuelve a hablar de sí mismo. De hecho, escribe este poema poco antes de morir. Por esa razón, presenta a su cuerpo como el de ese Narciso, viejo y exento de deseo sexual, a pesar de haber envidiado su modelo de macho prototípico, «he-man type», durante 
años. En cambio, ahora imagina que es puro e independiente, acogido en el refugio de sí mismo como madre e hijo. Es decir, el niño es en realidad Narciso que descansa en sí mismo sin necesitar a los demás. Lo mismo que le ocurrió a Narciso al enamorarse de su reflejo en el agua. Además, el profesor Arthur Kirsch aporta una explicación a esa dualidad sexual tan empleada por el autor, «Auden seriously as well as playfully imagines a return to the pre-Oedipal innocence of childhood, including the preOedipal union with his mother» (Kirsch, 2005: 171). En otras palabras, el fuerte vínculo familiar que existía entre Auden y su madre lo lleva a representarla en muchas de sus composiciones. Tal vez con la intención de demostrar la importancia que para él tenía la influencia materna en su vida. De hecho, en la obra de Auden hay otros casos en los que emplea las voces de madre e hijo para hablar consigo mismo, como ocurre en el ensayo The Prince's Dog (1962). Pero volviendo al análisis de A Lullaby, llegamos a la tercera estrofa:

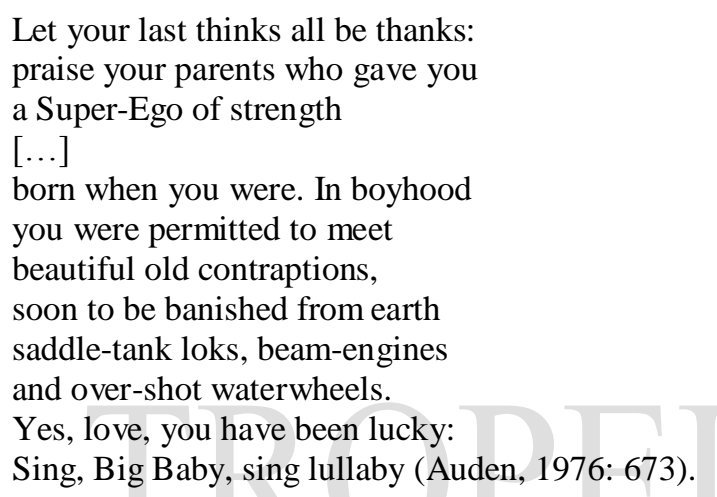

La voz materna le aconseja al hijo que debería agradecerle a sus padres la infancia que le han dado, la enriquecedora educación que lo ha convertido en un hombre crítico capaz de alcanzar un «yo» ideal, «a Super-Ego of strength», pues ha sido afortunado, al haber nacido en un hogar así. Es más, durante su adolescencia pudo conocer reliquias como la locomotora, motores de balancín y ruedas hidráulicas, debido a que es un joven afortunado, «Yes, love, you have been lucky». En efecto, el poeta angloamericano habla consigo, pero lo hace como si fuera su propia madre, recordándose lo afortunado que fue durante su niñez. El verso que cierra esta estrofa termina como todos los anteriores, con la madre diciéndole al hijo que cante la nana, «Sing, Big Baby, sing lullaby».

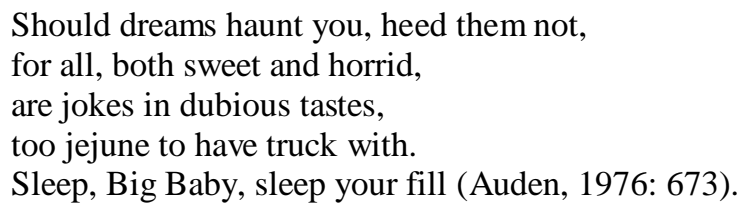

En la estrofa que cierra el poema, la madre aconseja al hijo que aunque los sueños le fascinen, es mejor que no les preste atención, porque tanto los agradables como los horribles son sólo bromas de dudoso gusto, «jokes in dubious taste», demasiado insustanciales para hacerles caso. Auden se convence de la irrealidad de los sueños, antes de dormirse. Todas las estrofas terminan con el mismo verso, excepto la última donde el poeta cambia «Sing, Big Baby, sing lullaby» por «Sleep, Big Baby, 
sleep your fill» («duerme, grandullón, duerme plácidamente»). La nana termina y la madre ha dormido al hijo.

En definitiva, lo que Auden ha hecho aquí ha sido tratar de reconciliarse con el hecho de no amarse ya más que a sí mismo, incitándose a un descanso merecido, diciéndose que los sueños eran falsos y que, después de todo, ha tenido una vida que ha valido la pena. Para reforzar la dulzura hacia sí mismo, ha usado las voces de madre e hijo, para no caer en el ridículo.

Sin embargo, a diferencia de W. H. Auden, que concibe el monólogo dramático a la manera de Robert Browning, la relación de Jaime Gil de Biedma con esta técnica es bien distinta. El poeta catalán no suele ocultarse en sus composiciones, mientras que el poeta victoriano sí lo hace, llegando a desaparecer por completo. Pero hay más, y es que Gil de Biedma tampoco suele objetivarse en sus poemas a través de un personaje histórico, como sí hace su maestro el sevillano Luis Cernuda, pues para el autor de Moralidades (1966) el monólogo dramático es realmente un diálogo consigo mismo. Como afirma José Teruel Benavente, para Jaime Gil de Biedma «el monólogo dramático se articula a través de las voces y personas del verbo, tanto en el estricto sentido gramatical: yo, tú y nosotros, como en el de las máscaras que han ido e irán apareciendo a lo largo de toda su poesía» (Teruel Benavente, 1995: 14). En este sentido, el monólogo dramático para Biedma es una situación dramática, en la que el poeta conversa con todos los personajes que forman su propia identidad. Se trata, por tanto, de una visión personalísima - y, sin duda, discutible - del monólogo dramático, pues Jaime Gil considera monólogos dramáticos a todos aquellos textos, en los que habla en primera persona, o a través del personaje «Jaime Gil de Biedma». Es decir, para el barcelonés, todos los poemas que incluyen la técnica del desdoblamiento son monólogos dramáticos. Por esa razón, para el autor catalán, esta es una técnica eficaz que le permite hablarse a sí mismo de sí mismo:

Lo fundamental en el monólogo dramático, en cuanto forma poética moderna, no estriba en la mera circunstancia de que se suponga dicho por alguien que no es el poeta; si así fuera, casi todas las canciones de amor, las epístolas y los discursos imaginarios de que está llena la poesía clásica serían monólogos dramáticos. Por el contrario, resulta perfectamente concebible un monólogo dramático cuyo protagonista sea el mismo autor. La voz que habla en un poema, aunque sea la del poeta, no es nunca una voz real, es sólo una voz posible, no siempre imaginaria, pero siempre imaginada. La persona poética es precisamente eso, impersonación, personaje (Gil de Biedma, 1980: 341).

Teniendo en cuenta lo anterior, no existe ningún personaje en los textos de Jaime Gil de Biedma que no sea el propio Jaime Gil de Biedma. Es decir, el «yo» con el que tratamos en los poemas del barcelonés es bien el poeta mismo, o bien el poeta siendo imaginado. De ahí que la diferencia sea mínima cuando hablamos de Jaime Gil de Biedma, o como dicen algunos críticos, de «Jaime Gil de Biedma». De hecho, el poeta catalán le habló a Carme Riera y Miguel Munárriz en una de sus últimas entrevistas sobre la ajenidad existente entre el «Jaime Gil de Biedma» presente en sus poemas y él como poeta, «el personaje que hablaba en mis poemas casi todo el tiempo que yo escribí era un personaje afín a mí en clase social, en cultura, en sensibilidad, pero que yo no identificaba conmigo mismo» (Riera y Munárriz, 1990). 
De modo que la obra poética de Jaime Gil de Biedma presenta, en términos generales, una disputa entre todos los personajes que habitan el «yo» del poeta, como ocurre en «Contra Jaime Gil de Biedma» y en «Después de la muerte de Jaime Gil de Biedma». Esto se debe a que el barcelonés es quien articula las distintas voces que tienen lugar en estos poemas dialógicos. En otras palabras, todos sus monólogos dramáticos tienen un carácter dialógico porque no son más que una forma de hablar consigo mismo como ocurre, por ejemplo, en «Pandémica y Celeste», de Moralidades, famoso monólogo dramático, en el que el autor presenta un juego de dos voces que le permiten mantener un diálogo con el lector, cuyo telón de fondo es la intimidad.

\title{
PANDÉMICA Y CELESTE
}

\author{
Imagínate ahora que tú y yo \\ muy tarde ya en la noche \\ hablemos de hombre a hombre, finalmente. \\ Imagínatelo, \\ en una de esas noches memorables \\ de rara comunión, con la botella \\ medio vacía, los ceniceros sucios, \\ y después de agotado el tema de la vida. \\ Que te voy a enseñar un corazón, \\ un corazón infiel, \\ desnudo de cintura para abajo, \\ hipócrita lector - mon semblable, - mon frère! (Gil de Biedma, 2010: 132).
}

Este fragmento es un ejemplo de cómo «Pandémica y Celeste» es un monólogo dramático escrito en forma de diálogo, donde el autor conversa con el lector. Para hablar con este último, el poeta catalán introduce una cita baudeleriana cargada de ironía, «hipócrita lector - mon semblable, - mon frère!», con la que pretende hallar un lector que no le juzgue, sino con el que pueda compartir sus experiencias. Así pues, para José Teruel Benavente, «la clave consustancial del monólogo dramático en Jaime Gil de Biedma consiste en una situación dramática que pone en escena la conversación interior mantenida por las personas que habitan en el seno dividido de su propia identidad» (Teruel Benavente, 2009: 682). Esto da lugar a que sus monólogos dramáticos sean realmente diálogos dramáticos consigo mismo.

No obstante, la postura que Jaime Gil de Biedma mantiene frente al monólogo dramático es, sin duda, matizable, porque el barcelonés considera monólogos dramáticos no sólo los textos de carácter dialógico, sino también aquellos en los que habla en primera persona. Por lo que si así fuera, todos los textos que componen su obra serían monólogos dramáticos y no lo son. Sin embargo, algunos críticos opinan como Biedma. De hecho, la profesora Joana Sabadell Nieto, por ejemplo, afirma que prácticamente todos los textos del barcelonés son monólogos dramáticos. Según Sabadell Nieto, «el monólogo dramático se caracteriza porque el autor crea una cierta distancia con respecto a su poema, gracias a que emplea una voz distinta a la suya» (Sabadell Nieto, 1997: 220).

Por lo tanto, aunque no todos los poemas del catalán catalogados como monólogos dramáticos cumplan íntegramente todas las características de esta técnica propuesta por Robert Langbaum, para 


\section{María Gracia Rodríguez Fernández}

la profesora Sabadell Nieto eso no es un hecho con el peso suficiente como para negar la total existencia de los monólogos dramáticos en la poesía de Jaime Gil de Biedma. Ahora bien, a diferencia de Joana Sabadell Nieto, para el profesor y crítico literario Javier González Rovira, Jaime Gil de Biedma no escribe ningún monólogo dramático, aunque sí habla de desdoblamientos del poeta a la hora de captar la experiencia. De hecho, González Rovira manifiesta su postura respecto a esta cuestión de la siguiente forma:

No podemos considerar como monólogo dramático, en sentido estricto, discursos en los que un «yo» no marcado como persona se dirige a un interlocutor (un personaje interno, el propio yo o el lector), como ocurre en algunos poemas de Luis Cernuda o del propio Jaime Gil de Biedma. Siguiendo a Langbaum, creemos que nuestro género implica una máscara identificable como tal (González Rovira, 1996: 34).

El profesor Javier González Rovira basa su opinión del tema en la lectura que hizo de un artículo de T. S. Eliot titulado The Three Voices of Poetry (1957), donde aprende los diferentes tipos de voces que establece Eliot y, por tanto, lleva al crítico a considerar que la técnica del monólogo dramático es la manifestación, tanto del personaje que se dirige a sí mismo, como a un auditorio. De hecho, tal y como ya apuntó Robert Langbaum, en los monólogos dramáticos no escuchamos la voz del autor como tal, sino la del personaje o personajes a través de los cuales se identifica, como ocurre en «Príncipe de Aquitania, en su torre abolida» de Poemas Póstumos (1968). Sin embargo, en el caso de Jaime Gil de Biedma, sólo hallamos un ejemplo en el que el poeta especifica quién habla en el texto y es en «Piazza del Popolo», de Compañeros de Viaje (1958). Se trata de un extenso monólogo dramático con forma de romance que, como explica en su artículo Verónica Leuci, «respeta su forma más habitual: una larga serie de octosílabos sin divisiones estróficas, con rima asonante en los versos pares, poblada de encabalgamientos, anáforas, repeticiones [y] paralelismos» (Leuci, 2010: 4). En él, el autor habla por medio de un personaje, cediéndole, en esta ocasión, la voz en primera persona explícitamente a María Zambrano. Por lo tanto, si en este texto el autor manifiesta claramente quién es la persona que habla, esto nos podría llevar a suponer que en todos aquellos poemas donde esta puntualización no aparece, no son, por consiguiente, monólogos dramáticos.

«Piazza del Popolo» es el primer poema social del barcelonés, en el que Jaime Gil de Biedma asume la vida y la personalidad de María Zambrano, indicando entre paréntesis que es ella quien habla en su poema, pues lo escribe bajo su influencia, al compartir con la filósofa y ensayista española el mismo sentimiento de afiliación y lealtad a las consignas comunistas.

PIAZZA DEL POPOLO

(Habla María Zambrano)

Fue una noche como ésta.

Estaba el balcón abierto

igual que hoy está, de par

en par. Me llegaba el denso

olor del río cercano

en la oscuridad. Silencio.

[...]

Aquí en la Plaza del Pueblo

se oía latir - y yo, 


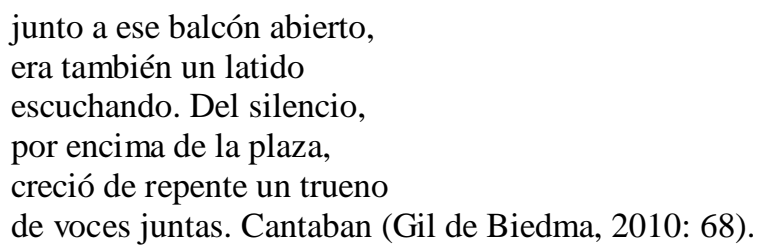

El poema empieza describiendo la similitud que guarda la noche en la que se escribe el poema con la noche de la que se habla. Una noche en la que una gran muchedumbre de personas se hallaba congregada en la «Plaza del Pueblo»» para manifestarse, a causa de la Guerra Civil Española. Guerra que provocó el exilio de intelectuales como, por ejemplo, María Zambrano que se vio afectada por las terribles consecuencias del conflicto. En «Piazza del Popolo», como explica en su artículo Anna Pont Bonsfills, «un arranque narrativo inaugura la elocución recreada de María Zambrano, en la que no faltarán los remansos líricos, ostensibles en las frecuentes repeticiones» (Pont Bonsfills, 1994: 252). Además, el «yo» poético describe cómo el silencio de la congregación da paso a una vociferación estruendosa, como protesta de los congregados en la plaza.

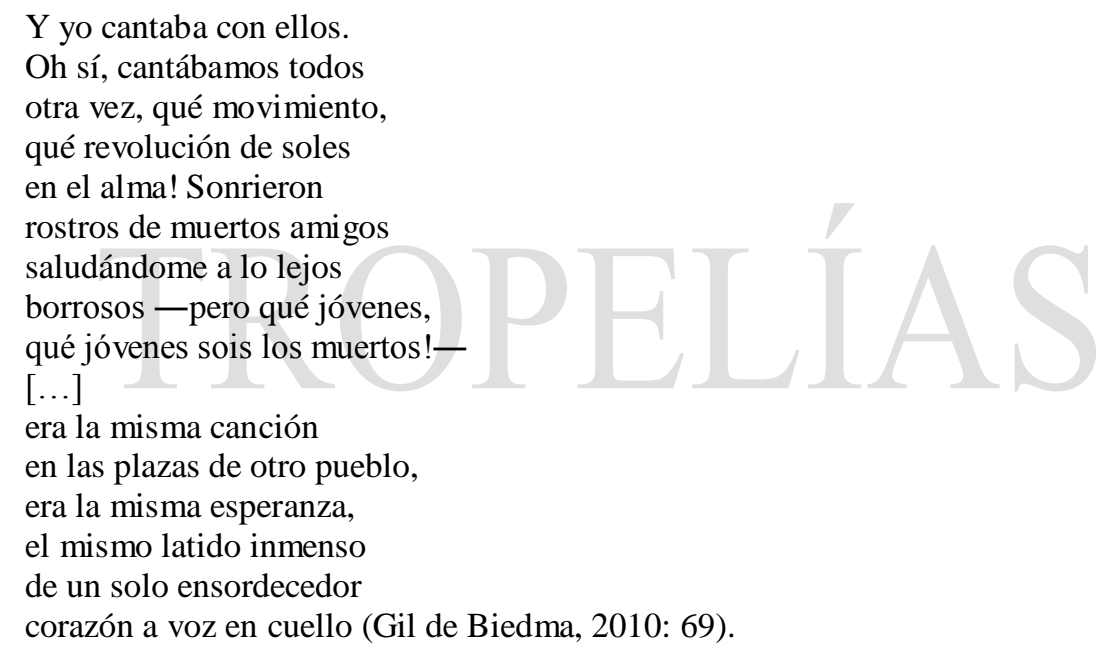

Al igual que los convocados en la plaza, la propia María Zambrano es víctima de una situación similar que la condena al exilio, por lo que se emociona mientras los observa desde el balcón de su casa en la «Piazza del Popolo», ya que se siente identificada con ellos. Por esa razón, canta con ellos al unísono, «Oh sí, cantábamos todos otra vez, que movimiento, qué revolución de soles en el alma». Este hecho la lleva a recordar aquellos «rostros de muertos amigos / saludándome a lo lejos», debido a que muchos de sus amigos murieron en el exilio por cuestiones políticas. Todos ellos ahora la saludan desde lo lejos. Todos muertos y jóvenes, al no haber experimentado el peso del paso del tiempo.

La escritora Laura Freixas en su artículo «Jaime Gil de Biedma» expone que «la multitud congregada en la plaza canta el himno revolucionario de los partidos comunistas y socialistas, como es La Internacional» (Freixas, 1997: 6), la canción más famosa del movimiento obrero, con la que los trabajadores reivindicaban sus derechos. Este hecho lleva a María Zambrano a recordar cómo ella y sus amigos también la cantaban, lo que la emociona profundamente. 


\title{
María Gracia Rodríguez Fernández
}

\author{
$\mathrm{Si}$, reconozco esas voces \\ cómo cantaban. Me acuerdo. \\ Aquí en el fondo del alma \\ absorto, sobre lo trémulo \\ de la memoria desnuda, \\ todo se está repitiendo. \\ $\mathrm{Y}$ vienen luego las noches \\ interminables, el éxodo \\ por la derrota adelante, \\ hostigados, bajo el cielo \\ que ansiosamente los ojos \\ interrogan. Y de nuevo \\ alguien herido, que ya \\ le conozco en el acento, \\ alguien herido pregunta, \\ alguien herido pregunta \\ en la oscuridad. Silencio. \\ [...] \\ los ojos, pero los ojos \\ Cierro \\ del alma siguen abiertos \\ hasta el dolor. Y me tapo \\ los oídos y no puedo \\ dejar de oír estas voces \\ que me cantan aquí dentro (Gil de Biedma, 2010: 70).
}

Este sentimiento de pesadumbre se enfatiza en los últimos versos, donde María Zambrano expone el dolor ilimitado que siente ante la realidad del exilio y el deseo, o apego sentimental que tiene, en palabras de Anna Pont Bonsfills, «al convencimiento ideológico emanado de las voces» (Pont Bonsfills, 1994: 260) que «me cantan aquí dentro». Es decir, ella escucha en su cabeza las voces de todos sus amigos condenados al exilio, lo que demuestra el dolor ilimitado del «yo» poético, pues ni cerrando los ojos, ni tapándose los oídos logra librarse de la angustiosa sensación, provocada por una melodía que suena, sin cesar, en su cabeza y que le recuerda el pasado.

«Piazza del Popolo» es, por tanto, un claro ejemplo de la mirada lúcida e irónica de Jaime Gil de Biedma capaz de expresarse a través de otra persona, para reivindicar sus quejas personales. En esta ocasión, el autor barcelonés asume la identidad de María Zambrano, con la que comparte el mismo sentimiento de desolación y crítica con respecto a los acontecimientos producidos en España, donde la guerra, la opresión política y las malas condiciones sociales provocan un sentimiento de alienación en todos aquellos ciudadanos condenados a una vida en el exilio.

En definitiva, este artículo sobre el monólogo dramático incluye las similitudes y diferencias que existen entre Wystan Hugh Auden y Jaime Gil de Biedma con respecto a esta práctica. En él, Auden, al igual que Robert Browning, considera monólogos dramáticos aquellos textos en los que cede directamente su voz a otro personaje, mientras que para Biedma merecerían la misma consideración todos los textos en los que habla en primera persona, o a través del personaje «Jaime Gil de Biedma». Esta opinión genera controversia, pues, si así fuera, todos los textos que componen su obra serían monólogos dramáticos, y no lo son. No obstante, a pesar de estas divergencias, esta sección incluye ejemplos en los que se observa cómo ambos autores ceden su voz a otros personajes. Estos ejemplos 
son los que aportan el grado de objetividad requerido en el discurso, pues la veracidad es mayor si la opinión que los poetas tienen sobre un tema determinado no la pronuncian ellos, sino otros. En el prefacio de The Sea and the Mirror Wystan Hugh Auden le cede su voz al maestro de pista, figura que ofrece, mediante metáforas, la visión que el poeta tiene de la vida y el arte, mientras que en «A Lullaby» le cede su voz a una madre, figura que utiliza para reconciliarse con lo que ha sido su vida. Auden expresa ternura y perdón hacia sí mismo, pero emplea a dos personajes, como son la Madonna y el Bambino, para no caer en el ridículo. Sin embargo, en el caso de Gil de Biedma hallamos el ejemplo de «Piazza del Popolo», en el que la voz que habla es la de María Zambrano. Esta figura le permite exponer las consecuencias que algunos intelectuales españoles padecieron durante el exilio del 39, exilio que el poeta catalán no experimentó. Además, después de estudiar exhaustivamente la técnica del monólogo dramático en la poética de Jaime Gil de Biedma, también concluimos que, si en «Piazza del Popolo» el autor indica que es María Zambrano la persona que habla en el texto, mientras que en otros textos no señala quién lo hace, todos aquellos poemas en los que esta puntualización no aparece, no son, por consiguiente, monólogos dramáticos.

\section{Referencias bibliográficas}

Auden, W. H. (1976): Collected Poems. London, Faber and Faber.

Blair, J. G. (1965): The Poetic Art of W. H. Auden. Princeton, Princeton University Press.

Boyd, M. (1976): W. H. Auden's The Sea and the Mirror: an Existential Interpretation of Shakespeare's Characters in The Tempest. Tesis doctoral, Texas University.

FREIXAS, L. (1997): «Jaime Gil de Biedma», en Retratos Literarios. Madrid, Espasa.

GIL DE BIEDMA, J. (1980): El pie de la letra. Ensayos 1955-1979. Barcelona, Crítica. (2010): Poesía y prosa. Ed. Nicanor Vélez. Barcelona, Galaxia Gutenberg.

GONZÁlez RoviRA, J. (1996): «El monólogo dramático y el soliloquio en la lírica española», Turia, XXXVII, 33.

KIRSCH, A. (2005): Auden and Christianity. Yale, Yale University.

Langbaum, R. (1963): The Poetry of Experience. The Dramatic Monologue in Modern Literary Tradition. New York, W.W. Norton \& Company.

LEUCI, V. (2010): Jaime Gil de Biedma y la tradición: reescrituras y relecturas en la poesía del «medio siglo», Actas del IX Congreso Argentino de Hispanistas celebrado en La Plata del 27 al 30 de abril de 2010, en http://www.memoria.fahce.unlp.edu.ar/trab_eventos/ev.1112/ev.1112.pdf (última consulta, 19-11-2015).

Mangini GonZÁlez, S. (1980): Gil de Biedma. Madrid, Júcar.

Pont Bonsfills, A. (1994): La estética en la ética. Poesía crítica española del medio siglo: Caballero, González, Gil de Biedma, Barral y Goytisolo. Tesis doctoral, Universidad de Lleida.

RIERA, C., y MunÁRriz, M. (1990): «Escribir fue un engaño (Entrevista con Jaime Gil de Biedma)», El País (14-1-1990). 
312 Tropelías. Revista de Teoría de la Literatura y Literatura Comparada, 25 (2016)

María Gracia Rodríguez Fernández

SABADEll NieTO, J. (1991): «El monólogo dramático: entre la lírica y la ficción», Tropelías. Revista de Teoría de la Literatura y Literatura Comparada, 2, pp. 177-186.

_- (1997): Fragmentos de sentido: la identidad transgresora de Jaime Gil de Biedma. Barcelona, PPU.

SÁNCHEZ PARDO, E. (2007): «El Silencio de Auden y el Clamor de la Historia», AEDEAN (Asociación Española De Estudios Anglo-americanos), 2.

TERUEl BenAVENTE, J. (1995): «Retórica de la experiencia en Las personas del verbo de Jaime Gil de Biedma», Revista Hispánica Moderna, 48/1.

(2009): «Dialogismo e identidad en la poesía de Jaime Gil de Biedma», en Carlos ALBA PeInAdo y Luis M. GonZÁLEZ, eds., Motivos \& Estrategias. Estudios en honor del Dr. Ángel Berenguer. Granada, Instituto Politécnico de Leiria-Universidad de Granada. 